\title{
Enamel Matrix Derivative in Diffusion Chamber Implanted Subcutaneously in Rat Induces Formation of Fibrous Connective Tissue Containing Abundant Blood Vessels
}

\author{
SATOSHI YOKOSE ${ }^{1}$, YUKA KATO $^{1}$, KATSUTOSHI MATSUMOTO ${ }^{1}$, PERRY R. KLOKKEVOLD ${ }^{2}$, \\ HENRY H. TAKEI ${ }^{2}$, HIROSHI KAWAZU ${ }^{3}$ and HIROSHI SAKAGAMI ${ }^{4}$ \\ ${ }^{1}$ Division of Endodontics and Operative Dentistry, Department of Restorative and Biomaterials Sciences, \\ Meikai University School of Dentistry, Saitama, Japan; \\ ${ }^{2}$ Division of Constitutive and Regenerative Sciences, Section of Periodontics, \\ School of Dentistry, University California Los Angeles, Los Angeles, CA, U.S.A.; \\ ${ }^{3}$ Section of Continuous Education, School of Dentistry, Meikai University, Saitama, Japan; \\ ${ }^{4}$ Meikai University Research Insititute of Odontology (M-RIO), \\ Meikai University School of Dentistry, Saitama, Japan
}

\begin{abstract}
Background: Enamel matrix derivative (EMD) is widely used for regeneration therapy in dental clinical situations, but the mechanism of EMD bioactivity remains obscure. To clarify this mechanism, we focused on the formation of connective tissue and blood vessels. The aim of this study was to confirm whether EMD induces the formation of connective tissue and blood vessels by using the diffusion chamber $(D C)$ technique. Materials and Methods: Individual DCs containing EMD (DC-EMD) or propylene glycol alginate (PGA) were implanted subcutaneously in rat dorsum. At 4 weeks after the implantation, histological analysis of DCs was performed using azan staining. Results: $D C$-EMD induced the formation of much larger amounts of connective tissue containing abundant blood vessels than did DC-PGA. Conclusion: The results indicated that EMD can induce the formation of both connective tissue and blood vessels. This bioactivity may contribute to the mechanism whereby EMD induces tissue regeneration.
\end{abstract}

Enamel matrix derivative (EMD) appears to stimulate the healing of soft tissue as well as that of bone tissue, and has

This article is freely accessible online.

Correspondence to: Satoshi Yokose, DDS, PhD, Division of Endodontics and Operative Dentistry, Department of Restorative and Biomaterials Sciences, Meikai University School of Dentistry, 1-1, Keyakidai, Saitama, 350-0283, Japan. Tel/Fax: +81 492792736, e-mail: s-yokose@dent.meikai.ac.jp

Key Words: Enamel matrix derivative, diffusion chamber, connective tissue, blood vessels, rat. been widely applied in regeneration therapy for implant, periodontic, and endodontic treatments (1-3). EMD has been shown to stimulate osteoblast proliferation and differentiation $(4,5)$ and collagen production $(6)$, implying that EMD may be a strong inducer of tissue mineralization. On the other hand, in vitro experiments have indicated that EMD has little effect on the bioactivities of osteoblasts or fibroblasts $(7,8)$. To resolve this contradiction, we hypothesized that EMD stimulates angiogenesis in tissues. In fact, some studies have reported that EMD strongly stimulates the accumulation of vascular endothelial growth factor (VEGF) in connective tissue $(9,10)$, thereby stimulating angiogenesis. This effect may represent a critical contribution to the wound-healing process in both soft and hard tissues. To test this hypothesis, we focused on the effects of EMD on angiogenesis, including the establishment of a unique experimental approach employing the diffusion chamber (DC) technique (11).

The DC technique was originally developed to examine osteoblast differentiation and the effects of various growth factors on osteoblast differentiation and proliferation (12). We placed EMDs into DCs and then implanted the resulting DC-EMDs subcutaneously in rat. This model was used to examine the effects of EMD on angiogenesis.

In the present study, we examined the effects of EMD on angiogenesis using the DC technique in combination with histochemical analysis.

\section{Materials and Methods}

DCs were assembled using a Millipore filter membrane in combination with plastic rings (pore size, $0.45 \mu \mathrm{m}$; internal diameter, $9 \mathrm{~mm}$; thickness, $2 \mathrm{~mm}$; Millipore Corporation, Bedford, MA, USA) (Figure 1A). After sterilization using ethylene oxide gas, 


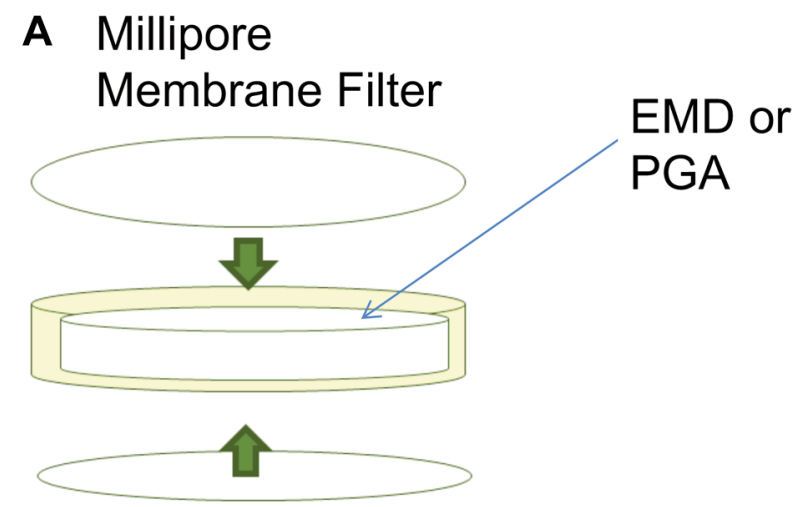

B

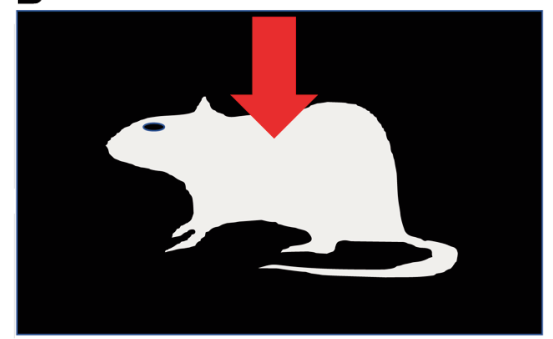

Figure 1. Schematic of the assembly of a diffusion chamber (DC), which is composed of two pieces of membrane filter and a plastic ring. The enamel matrix derivative (EMD) or propylene glycol alginate (PGA; control matrix) then was inserted into the $D C(A)$. The resulting $D C-E M D$ and $D C-P G A$ then were implanted subcutaneously in rat dorsum $(B)$.

EMD (Emdogein, Institute Straumann JP, Tokyo, Japan) was placed in the DC through a hole in the ring, which then was plugged; this construct was designated a DC-EMD. A control was generated using propylene glycol alginate (PGA; Fujifilm Wako Pure Chemical Corporation, Osaka, Japan), which is normally included in EMD as a carrier material. Specifically, a negative control DC (designated a DC-PGA) was constructed by placing PGA in a DC as above.

Animal experiments were performed according to a protocol approved by the Animal Affairs Committee of Meikai University (approval no. A1739). Six female Sprague-Dawley rats, 8 weeks of age, were used in the experiment. Each rat had one DC-EMD and one DC-PGA implanted subcutaneously on the right and left sides, respectively, of the dorsum (Figure 1B). At 4 weeks postimplantation, the DCs were recovered and fixed in $10 \%$ neutral buffered formalin. The DCs then were embedded in paraffin wax and subjected to serial sectioning. The resulting sections were stained with azan to visualize the structures of connective tissue and blood vessels. Staining was performed according to the technique described by Fukuda et al. (13). Specifically, the sections were immersed in $10 \%$ $(\mathrm{w} / \mathrm{v})$ potassium dichromate solution containing $10 \%(\mathrm{w} / \mathrm{v})$ trichloroacetic acid for $15 \mathrm{~min}$. After washing with distilled water (DW), the sections were stained with $0.1 \%$ (w/v) azocarmine G (Fujifilm Wako Pure Chemical Corporation) for $5 \mathrm{~h}$. After washing with DW, the sections were immersed in $0.1 \%(\mathrm{v} / \mathrm{v})$ aniline in $95 \%$ (v/v) ethanol for $5 \mathrm{~s}$ and then in $0.1 \%(\mathrm{v} / \mathrm{v})$ acetic acid in $95 \%(\mathrm{v} / \mathrm{v})$ ethanol for $1 \mathrm{~min}$. The sections were washed with DW, and then incubated in 5\% (w/v) phosphotungstic acid solution for $1 \mathrm{~h}$. After washing with DW, the sections were stained with aniline blue-orange G solution (Fujifilm Wako Pure Chemical Corporation) for $1 \mathrm{~h}$. The stained sections then were observed under light microscopy, including counting of the number of blood vessels per field.

The results are expressed as mean \pm SD. Statistical analysis between the two groups was evaluated using the Wilcoxon $t$-test. A $p$-value less than 0.05 was considered significant.

\section{Results}

Figure 2 shows examples of DCs recovered from a rat at 4 weeks post-implantation. Each DC-EMD was surrounded by fibrous connective tissue. In contrast, each DC-PGA was surrounded by only a small amount of connective tissue.

Figure 3 shows histological structures for DCs recovered from rats at 4 weeks post-implantation. The sections of azanstained DCs-EMD demonstrated the presence of connective tissue composed of blue-stained collagen bundles containing abundant blood vessels filled with red blood cells. On the other hand, the sections of azan-stained DCs-PGA revealed the presence of a thin layer of connective tissue covering the membrane. This tissue layer contained few blood vessels.

Figure 4 shows the results of counting the number of blood vessels in the connective tissue on each DC. The number of blood vessels in the connective tissue on the DCs-EMD was significantly greater compared to that on the DCs-PGA.

\section{Discussion}

EMD is a strong inducer of cell differentiation for various tissues. Multiple experiments have reported that EMD can stimulate wound healing in a number of different tissues, with these effects depending on the orchestrated bioactivities of many kinds of cells during wound healing. Although some articles have reported that EMD stimulates osteoblast differentiation $(4,5)$, other research has not detected biological effects in in vitro systems $(7,8,14)$. We hypothesized that this apparent contradiction may reflect the intimate role of vascularization in tissue differentiation. If the bioactivities of EMD reflect the induction of angiogenesis, this putative contradiction would be partially resolved. Because the environmental changes caused by angiogenesis are unique in living organisms and are not seen under the culture conditions. To examine the role of EMD in the induction of vascularization, we employed the DC technique as part of our experimental design. Notably, EMD placed in a DC would be expected to provide slow diffusion of EMD and associated factors through the membrane, out of the chamber, and into the body, facilitating analysis of the bioactivities induced by EMD. In fact, DCs implanted subcutaneously in rat have been shown to provide various bioactivities induced by transforming growth factor- $\beta$, bone morphogenetic proteins, fibroblast growth factors, and 


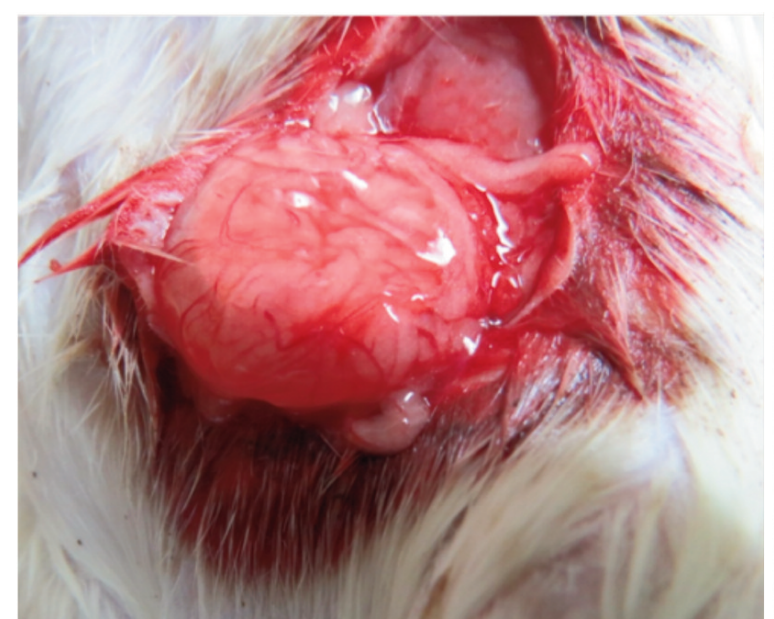

DC-EMD

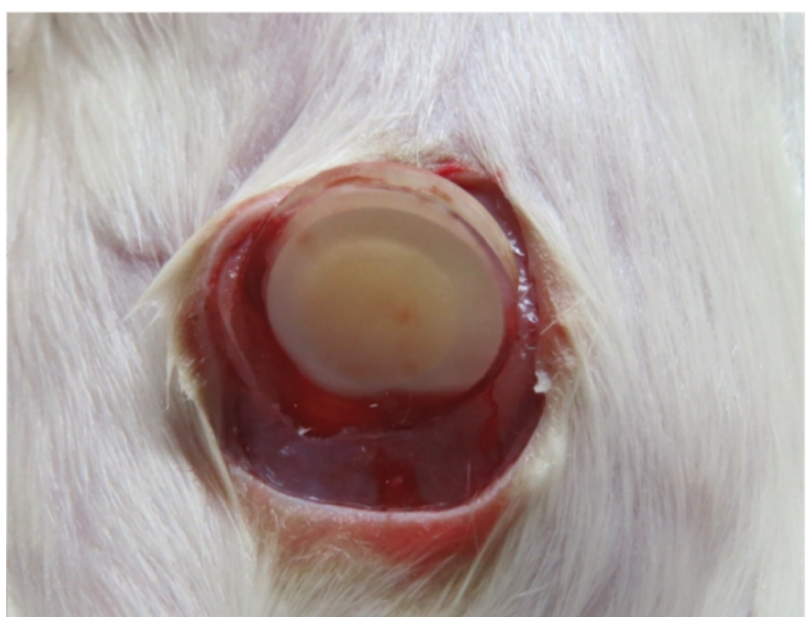

DC-PGA

Figure 2. At 4 weeks after subcutaneous implantation, the diffusion chambers with enamel matrix derivative (DC-EMD) or propylene glycol alginate (DC-PGA) were recovered from rats.

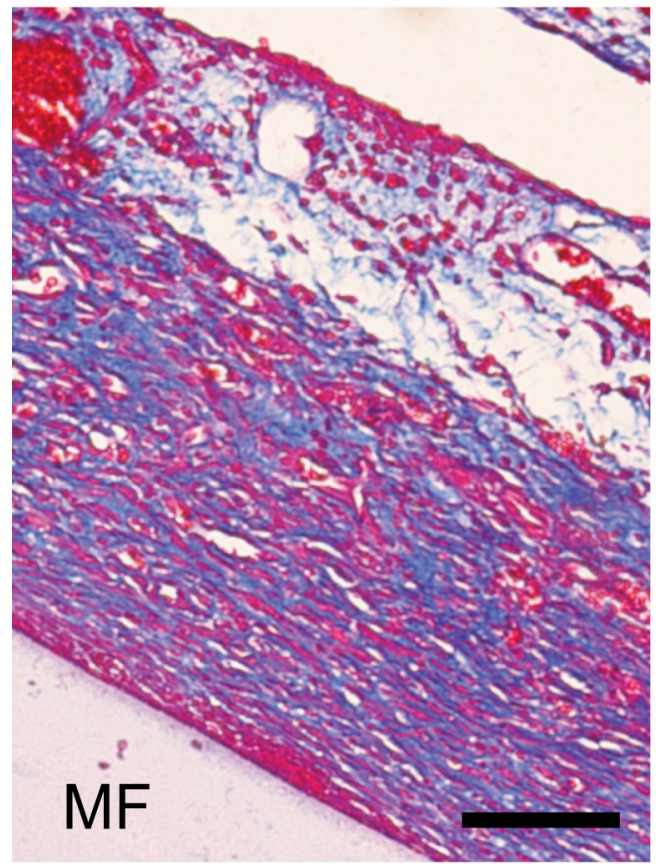

DC-EMD

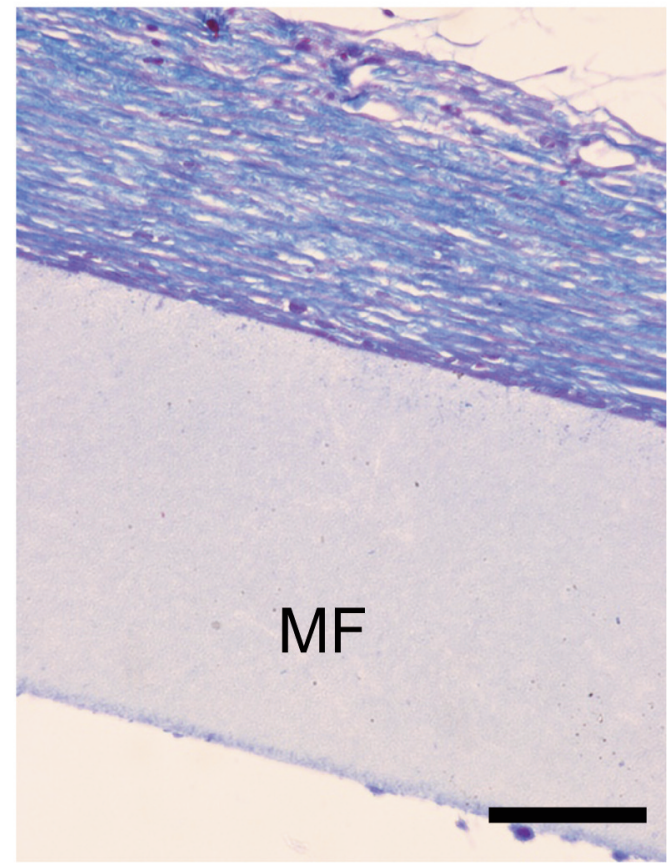

DC-PGA

Figure 3. Azan staining was performed on sections of the diffusion chambers with enamel matrix derivative (DC-EMD) or propylene glycol alginate (DC-PGA, control matrix). Collagen bundles stained with blue and blood vessels filled with red blood cells can be clearly seen. Bar: 50 um. MF: Millipore filter membrane.

platelet-derived growth factors (15). On the other hand, DCs also can be employed to examine systemic factors. We have analyzed the mechanism of post-menopausal osteoporosisinduced estrogen deficiency using DCs (11). Experiments using DCs containing osteoblast-like cells implanted subcutaneously in ovariectomized rats demonstrated that osteoblast differentiation is controlled by insulin-like growth factors acting as systemic factors under conditions of 


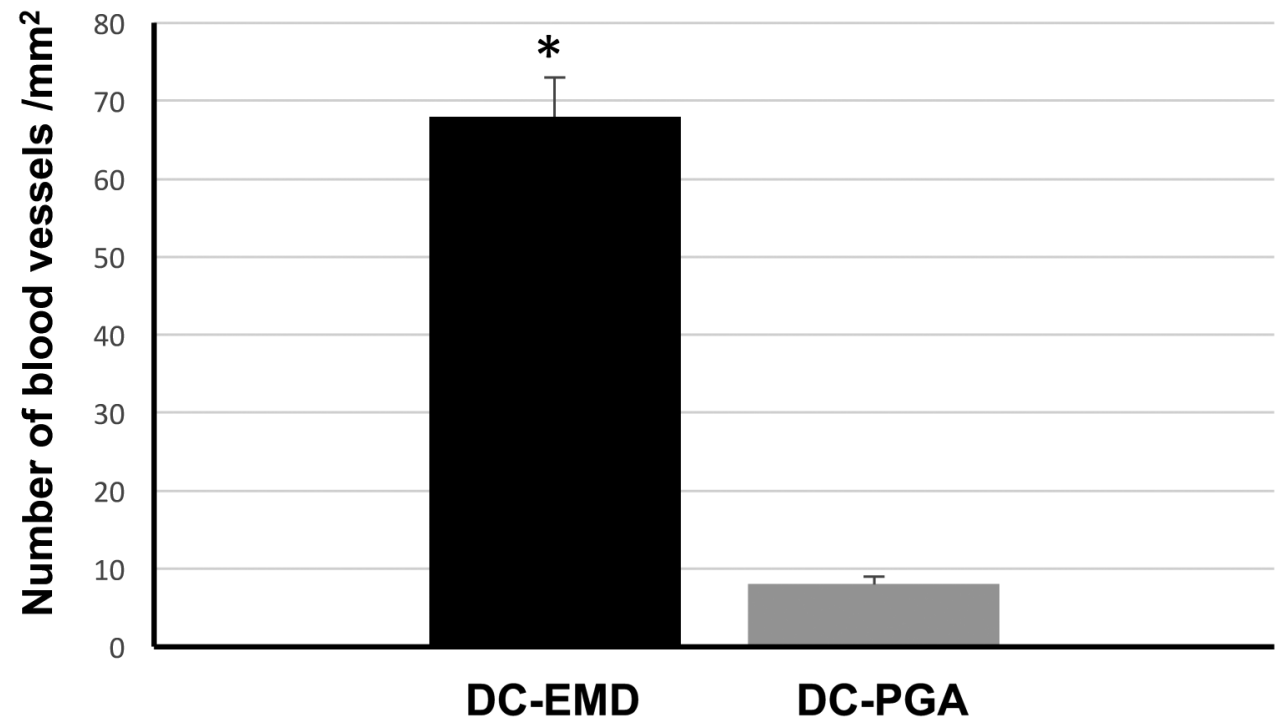

Figure 4. The number of blood vessels was counted in the connective tissue induced by each of diffusion chambers with enamel matrix derivative $(D C-E M D)$ or propylene glycol alginate (DC-PGA, control matrix). Data are presented as mean $\pm S D$ of six DCs. *Significantly different from DC$P G A$ at $p<0.05$ by Wilcoxon t-test).

estrogen deficiency. For these reasons, we used DCs to examine the bioactivities of EMD. The results of our experiment demonstrated that EMD can strongly induce the formation of connective tissue with abundant blood vessels. Previous work has shown that EMD induces VEGF expression in endothelial cells (9) and that the proliferation of those cells is stimulated by $\operatorname{VEGF}(9,10,16)$. Thus, EMD is capable of inducing vascularization in various tissues. Given that EMD is employed clinically in dentistry for tissue regeneration, it is notable that angiogenesis has a key role in the proliferation and differentiation of various tissues.

It has been reported that EMD induces VEGF expression in endothelial cells, a phenomenon intimately correlated with angiogenesis. On the other hand, the present work demonstrated that implanted DCs containing EMD apparently induce the formation of connective tissue containing abundant blood vessels. Together, these observations indicate that EMD induces the formation not only of blood vessels, but also fibrous connective tissue. The fibrous connective tissue induced by EMD presumably contains precursor cells that can differentiate into various kinds of tissues (17), and the resulting blood vessels play an active role in both cell proliferation and differentiation. We postulate that the strong induction of both fibrous connective tissue and blood vessel formation may be an important aspect of the biological effects of EMD.

In conclusion, we demonstrated that EMD in DCs induces the formation of fibrous connective tissue containing abundant blood vessels. These results suggest that EMD may find applications in regeneration therapy for multiple tissue types.

\section{Conflicts of Interest}

The Authors declare that they have no conflicts of interest.

\section{Authors' Contributions}

S.Y. performed all experiments and wrote the article. Y.K. and K.M. supported the animal experiments. H.S., P.R.K., T.H., and H.K. edited and revised the article.

\section{Acknowledgements}

The Authors are especially grateful to Dr. Yuko Nakamura (deceased 13 January 2020) for her help with the animal experiments.

\section{References}

1 Sculean A, Schwarz F, Becker J and Brecx M: The application of an enamel matrix protein derivative (Emdogain) in regenerative periodontal therapy: a review. Med Princ Pract 16(3): 167-180, 2007. PMID: 17409750 . DOI: $10.1159 / 000100386$

2 Kémoun P, Gronthos S, Snead ML, Rue J, Courtois B, Vaysse F, Salles JP and Brunel G: The role of cell surface markers and enamel matrix derivatives on human periodontal ligament mesenchymal progenitor responses in vitro. Biomaterials 32(30): 7375-7388, 2011. PMID: 21784516. DOI: 10.1016/j.biomaterials.2011.06.043

3 Wang HH, Sarmast ND, Shadmehr E, Angelov N, Shabahang S and Torabinejad M: Application of enamel matrix derivative (Emdogain) in endodontic therapy: A comprehensive literature review. J Endod 44(7): 1066-1079, 2008. PMID: 29580724. DOI: $10.1016 /$ j.joen.2018.02.012 
4 He J, Jiang J, Safavi KE, Spångberg LS and Zhu Q: Emdogain promotes osteoblast proliferation and differentiation and stimulates osteoprotegerin expression. Oral Surg Oral Med Oral Pathol Oral Radiol Endod 97(2): 239-245, 2004. PMID: 14970783. DOI: 10.1016/j.tripleo.2003.10.005

5 Zou R, Wan W, Li J, Du C, Wang Y, Qian T and Niu L: Combining enamel matrix proteins with mechanical stimuli potentiates human periodontal ligament fibroblasts proliferation and periodontium remodeling. Histol Histopathol 33(8): 825833, 2018. PMID: 29485179. DOI: 10.14670/HH-11-978

6 Wada Y, Yamamoto H, Nanbu S, Mizuno M and Tamura M: The suppressive effect of enamel matrix derivative on osteocalcin gene expression of osteoblasts is neutralized by an antibody against TGF-beta. J Periodontol 79(2): 341-347, 2008. PMID: 18251649. DOI: 10.1902/jop.2008.070197

7 Hama H, Azuma H, Seto H, Kido J and Nagata T: Inhibitory effect of enamel matrix derivative on osteoblastic differentiation of rat calvaria cells in culture. J Periodontal Res 43(2): 179-185, 2008. PMID: 18302620. DOI: 10.1111/j.1600-0765.2007.01010.x

8 Aspriello SD, Zizzi A, Spazzafumo L, Rubini C, Lorenzi T, Marzioni D, Bullon P and Piemontese M: Effects of enamel matrix derivative on vascular endothelial growth factor expression and microvessel density in gingival tissues of periodontal pocket: a comparative study. J Periodontol 82(4): 606-612, 2011. PMID: 20843235. DOI: $10.1902 /$ jop.2010.100180

9 Kauvar AS, Thoma DS, Carnes DL and Cochran DL: In vivo angiogenic activity of enamel matrix derivative. J Periodontol $81(8)$ : 1196-1201, 2010. PMID: 20370422. DOI: 10.1902/jop.2010. 090441

10 Yokose S, Ishizuya T, Ikeda T, Nakamura T, Tsurukami H, Kawasaki K, Suda T, Yoshiki S and Yamaguchi A: An estrogen deficiency caused by ovariectomy increases plasma levels of systemic factors that stimulate proliferation and differentiation of osteoblasts in rats. Endocrinology 137(2): 469-478, 1996. PMID: 8593791. DOI: 10.1210/endo.137.2.8593791

11 Okubo K, Kobayashi M, Takiguchi T, Takada T, Ohazama A, Okamatsu Y and Hasegawa K: Participation of endogenous IGFI and TGF-beta 1 with enamel matrix derivative-stimulated cell growth in human periodontal ligament cells. J Periodontal Res 38(1): 1-9, 2003. PMID: 12558931. DOI: 10.1034/j.1600-0765. 2003.01607.x
12 Fukuda K, Kamoshida Y, Kurokawa T, Yoshida M, FujitaYamaguchi $\mathrm{Y}$ and Nakata M: Migration of breast cancer cells into reconstituted type I collagen gels assessed via a combination of frozen sectioning and azan staining. Biosci Trends 8(4): 212216, 2014. PMID: 25224627. DOI: 10.5582/bst.2014.01090

13 Esposito M, Grusovin MG, Papanikolaou N, Coulthard P and Worthington HV: Enamel matrix derivative $(\operatorname{Emdogain}(\mathrm{R}))$ for periodontal tissue regeneration in intrabony defects. Cochrane Database Syst Rev 2009(4): CD003875, 2009. PMID: 19821315. DOI: 10.1002/14651858.CD003875.pub3

14 Miron RJ, Shuang Y, Sculean A, Buser D, Chandad F and Zhang $\mathrm{Y}$ : Gene array of PDL cells exposed to Osteogain in combination with a bone grafting material. Clin Oral Investig 20(8): $2037-$ 2043, 2016. PMID: 26744181. DOI: 10.1007/s00784-015-1702-2

$15 \mathrm{Ma} \mathrm{J}$, Lai G and Lu Z: Effect of $410 \mathrm{~nm}$ photodynamic therapy with hemoporfin on the expression of vascular endothelial growth factor (VEGF) in cultured human vascular endothelial cells. Lasers Med Sci 34(1): 149-155, 2019. PMID: 30350123. DOI: 10.1007/s10103-018-2649-8

16 Breuing K, Eriksson E, Liu P and Miller DR: Healing of partial thickness porcine skin wounds in a liquid environment. J Surg Res 52(1): 50-58, 1992. PMID: 1548868. DOI: 10.1016/00224804(92)90278-8

17 Ten Cate AR, Bartold PM, Squier CA and Nanci A: Repair and regeneration of oral tissues. In: Ten Cate's Oral Histology Development, Structure and Function. Nanci A (ed). St. Louis, Mosby, pp. 397-416, 2003.
Received November 7, 2020

Revised November 23, 2020

Accepted November 25, 2020 